EESTI NSV TEADUSTE AKADEEMIA TOIMETISED 1953. II k., nr. 2 ИЗВЕСТИЯ АКАДЕМИИ НАУК ЭСТОНСКОИ ССР 1953. Том II, N 2

\title{
ИММУНОЛОГИЧЕСКИЕ СДВИГИ В ОРГАНИЗМЕ БОЛЬНЫХ ПРИ ХРОНИЧЕСКОМ ОСТЕОМИЭЛИТЕ
}

\author{
А. М. ХОВАНОВА, \\ кандидат медицинских наук
}

Правильное понимание глубины всех взаимосвязей макроорганизма с микроорганизмом настоятельно требует всестороннего изучения не только качественных признаков микроба, но также и иммунологических реакций, которыми макроорганизм отвечает на внедрившихся микробов.

Современная постановка более широкого изучения микробных ассоциаций гнойных ран и особенно ран хронических остеомиэлитов является одним из важных звеньев успешного разрешения проблемы раневых ннфекций.

В 1939 году Гамалея $\left({ }^{6}\right)$ и в 1948 году Зильбер $\left({ }^{14}\right)$ указывали, что образование защнтных антител в макроорганизме происходит в ответ на действие внедрившихся патогенных микроорганизмов.

По данным многих исследователей, является совершенно очевидным, что в ранах хронически протекающих остеомиэлитов основными представителями микробной флоры являются стафилококки и стрептококки. Более.глубокое изучение патогенных свойств также указывает на то, что большой процент пиококков обладает способностью коагулировать плазму крови, лизировать эритрощиты и фибрин и, наконец, продуцировать в большом количестве фермент гиалуронидазу. Все эти данные позволяют считать пиококков, находящихся в ранах при хроническом остеомиэлите, в основном патогенными микроорганизмами, а следовательно, способными вызвать соответствующие иммунологические реакции в макроорганизме.

Для установления налнчия иммунологической реакции организма в ответ на находящихся в нем длительное время патогенных стафилококков и стрептококков при хроническом остеомиэлите нами была принята за показатель реакция агглютинации, которая косвенно указывает на образование в организме антител - агглютининов.

Положительную реакцию агтлютинации в сыворотках кроликов, иммунизированных патогенными стафнлококками, Қолле и Отто получали еще в 1902 году. В 1936 году Сажина, Николаевская и Каневич, по данным Манушакяна $\left({ }^{20}\right)$, наблюдали положительную реакщию агглютинашии со стафилококками у больных стафилодермией. Манушакяну в 1940 году удалось установить у 62 процентов больных пиодермией положнтельную реакцию агглютинации в разведениях от $1: 60$ до $1: 1000$, тогда как в контролях с гетерогенными сыворотками н сапрофитными стафнлококками агтлютинации не получалось совсем или она была в разве- 
дениях не выше чем 1:40. На основании этих данных автор приходит к заключению, что высокий титр агглютининов в сыворотках больных стафилодермией служит неоспоримым доказательством глубоких иммунологических изменений, вызываемых пиогенной инфекцией во всем организме. В 1945-1946 годах появились работы Гращенкова и его сотрудников Сахарова и Гудковой $\left({ }^{8-10}\right)$, в которых они придают огромное значение образующимся агтлютининам в органнзме людей, страдающих хроническим остеомиэлитом. Они считают, что в крови больного антитела к гемолитическим стрептококкам нарастают и достигают максимума на $17-25$-й день заболевания, а к-стафилококкам нарастание антител наблюдается на 35 -й день и позднее. Таким образом, указывают авторы, чем длительнее находится в ране микроб, тем больше антител вырабатывается к нему. Количество агтлютининов к стафилококкам, как наиболее длительно задерживающимся в ране микробам, иногда достигает разведений $1: 10000-1: 30000$, что никогда не имеет места при обычной инфекции. Таранухина $\left({ }^{22}\right)$, Иоффе $\left({ }^{15-17}\right)$, Қац $\left({ }^{18}\right)$ и другие исследователи также указывают на большое значение иммунологических реакций в макроорганизме при раневой ннфекции. Но вместе с тем следует указать, что антигенные свойства стафилококков и стрептококков микробиологами еще мало изучены. Совершенно недостаточно уделялось внимания всем иммунологическим реакциям в организме больного с гнойной инфекцией, хотя изучение антигенной активности стафилококков и стрептококков представляөт несомненно важный и интересный раздел проблемы раневых инфекций.

Целью наших исследованнй является изучение иммунологических сдвигов в организме больных, страдающих хронической формой остеомиэлита.

Изучение а๋тигенных свойств стафилококков и стрептококков по наличию агглютининов к ним в сыворотке больных остеомиэлитом нами проводилось в следующих трех направлениях: 1) устанавливалось наличие агтлютининов, титр и динамика его в сыворотке больных к выделенным от них штаммам стафилококков и стрептококков; 2) устанавливалось наличие агтютининов к изучаемым штаммам пиококков в сыворотке крови здоровых людей; 3) устанавливалась агтлютннабильность изучаемыг штаммов стафилококков н стрептококков в гетерогенных сыворотках, т. е. в сыворотках друтих болыных, путем постановкн так называемой перекрестной реакщии агтлютинации.

Для этого нами были изучены титры агглютининов и их динамика в крови 103 больных, страдающих хроническим остеомиэлитом. В качестве антигенов служили выделенные из раны этих больных стафилококки или стрептококки.

При выделении чистых культур пиококков и постановке с-ними реакции агтлютинации в сыворотке крови больных пользовались обычной методикой.

Как правкло, все штаммы пиококков, выделенных из раны, проверялись на патогенность по прнзнакам гемолиза, плазмокоагуляции, фибринолизиса и наличия гиалуронидазы. В результате оказалось, что все штаммы пиококков в среднем в пределах $50-94 \%$ обладали указанными признаками, т. е. они в болышинстве своем являлись патогенными микроорганизмами.

От 103 больных всего было выделено стафилококков золотисто-желтых 97 штаммов, белых - 72 штамма и стрептококков - 51 штамм. Соответственно поставлено реакций агглютинации с первыми - 268, со вторыми - 254 и с третьими - 72 .

Результативные данные показывают, что постановка реакции агтлю- 
тинации с сывороткой крови и штаммами пиококков, выделенными от одного и того же больного, констатирует наличне достаточно высоких гитров агллютининов в крови больных хроническим остеомиэлитом.

Так, например, из 268 реакций с золотисто-желтыми стафнлококками 198 реакций дали положительный результат в разведениях 1:8001:2000; 23 реакции — в разведениях 1:2600-1:3000, 5 реакций - в разведении 1:5000 и выше и лишь 42 реакщии дали положительный результат в разведенин 1:400-1:600. Из 254 реакщий с белыми стафилококками положительный результат дали 220 реакций в разведениях $1: 800-1: 2000,14$ реакций - в разведениях $1: 2600-1: 3000$ и лишь 20 реакций дали положительный результат в разведениях $1: 400$ 1:600. Во всех наших опытах наличие в сыворотке больных агглютинации к белым стафнлококкам в титре выше пем $1: 3000$ обнаружено не

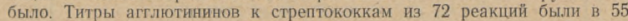
реакциях в разведениях 1:800-1:2000, в одном случае титр был зафнкснрован в разведении $1: 2600$, и 16 реакций дали положительный результат в разведениях 1:400-1:600.

Итак, наличие агглютининов в крови больных хроническим остеомиэлитом к выделенным от них же пиококкам показывает достаточно высокие титры. Следовательно, штаммы стафилококков и стрептококков при этом заболевании являются антигенно активныги и вполне способными вызвать соответствующие иммунологическне реакцин в макроорганизме.

Изучение динамики аглютининов к пиококкам в сыворотке обследованных больных показало, что по характеру течения клиннческого процесса и применяемой терапии всех 103 больных можно распределить примерно на три группы.

1. Больные (12 человек, или $11,6 \%)$, у которых титр агтлютининов в крови держится на довольно высоком уровне. Но как только применяется успешная хирургическая операция и рана зажнвает без нагноительных осложнений, титр агтлютининов начинает заметно снижаться. Как видно, фактор раздражения иммунологической системы организма микробами ликвидируется, образование антител сннжается, а затем прекрашается совершенно (таблица 1).

2. Больные (62 человека, нли $60,2 \%)$, у которых титр агтлютининов в крови был достаточно высоким и еше более повышался после хирургической операции $(1: 2000-1: 3000)$, удерживаясь на этом уровне в течение длительного промежутка времени (таблица 2).

Следует предполагать, что повышение титра агглютининов после операционного вмешательства пронсходит вследствие недостаточно радикального проведения хирургической обработки инфицированной раны, а также вследствне наличия некротического участка кости. В этих случаях в ране остается некоторое количество некротических тканей (кости, мышщы и т. д.), которые являются питательным субстратом н создают условия для дальнейшего развитня оставшейся в ране гноеродной инфекции, в частности стафилококков и стрептококков.

Такое положение ведет к образованию депо пиогенной инфекции, являющейся раздражителем иммунологической системы макроорганизма, которая начннает усиленно вырабатывать антитела.

Следовательно, организм больного дополннтельно вступает в активную фазу иммунологической борьбы с имеющейся в нем гноеродной ннфекцией. Несмотря на наличие после операщии достаточно высокого титра агглютинннов в крови у таких больных, рана чаще всего заживает нормально, но нередко образуется отдаленный рецидив остеомиэлнта с наличием свища.

Можно думать, что в таких случаях полного анатомического выздо- 
ровления в ране не наступило потому, что там нет полного бактериального выздоровления. А поэтому лечащий хирург должен проявнть соответствующую настороженность в отношении возможности образования у таких больных скрытого очага инфекшин, ведущего к образованию рецидивирующего остеомнэлита гематогенного порядка.

Tаблица I

Титры arrлютининов в крови больного Г. к стафилококкам и стрептококкам

\begin{tabular}{|c|c|c|c|c|c|}
\hline \multirow{2}{*}{$\begin{array}{l}\text { Tuтры } \\
\text { arrnютининоб }\end{array}$} & \multicolumn{4}{|c|}{$\begin{array}{c}\text { Дата постановku peakuuu } \\
\text { arrлютинациu }\end{array}$} & \multirow{2}{*}{$\begin{array}{c}\text { Дага } \\
\text { операциu }\end{array}$} \\
\hline & 201 & $10 \mathrm{III}$ & $18 \mathrm{III}$ & $23 \mathrm{III}$ & \\
\hline \multicolumn{6}{|l|}{$1: 1000$} \\
\hline $1: 900$ & & & & & $\begin{array}{l}291 \text { - } \\
\text { cekbecrporomus } \\
\text { Segpa u тrзовов } \\
\text { kости }\end{array}$ \\
\hline \multicolumn{6}{|l|}{$1: 800$} \\
\hline \multicolumn{6}{|l|}{$1: 700$} \\
\hline \multicolumn{6}{|l|}{$1: 600$} \\
\hline \multicolumn{6}{|l|}{$1: 500$} \\
\hline \multicolumn{6}{|l|}{$1: 400$} \\
\hline $1: 200$ & & & & & \\
\hline
\end{tabular}

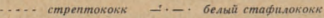

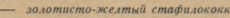

3. Больные (29 человек, или $28,2 \%$ ), в крови у которых титры агтлютининов к выделенным от них стафилококкам и стрептококкам держатся на высоком уровне $(1: 800-1: 2600)$ на протяжении длительного времени (таблица 3).

Эта групша больных лечилась консервативно. С нарастанием антител в крови течение клинического процесса явно улучшалось, свищи закрывались и больные выписывались из клиники без оперативного вмешательства. Но здесь, как и у второй группы больных, следует иметь в 
виду возможное отсутствие полного прекращения анатомического и бактериального раневых процессов, на что указывает наличие высоких титров агтлютининов и что может привести также к образованию рен цидива.

В наших исследованиях неоднократно приходилось встречаться со случаями, когда больные, выписавшиеся из клиники с полным клиниче-

таблица 2

Титры агтлютининов в крови больного П. к стафилококкам и стрептококкам

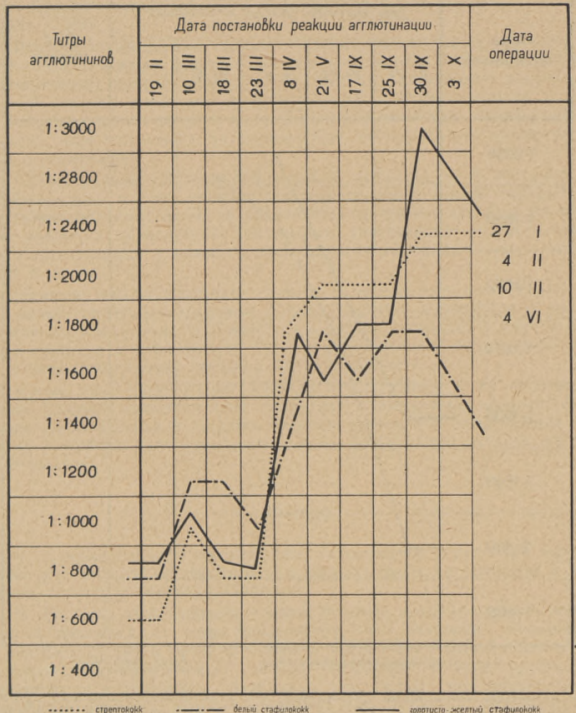

ским выздоровлением, но с высоким титром агглютининов в крови как после операции, так и консервативного лечения, через некоторое время вновь поступали в клинику с рецидивом свища.

Полученная в наших опытах динамика титров агглютининов в крови больных остеомиэлитом позволяет считать, что антигенная активность стафилококков и стрептококков при данном заболевании играет далеко 
не второстепенную роль и что наличие их в ране вызывает явно выраженную иммунологическую реакцию со стороны макроорганизма. Следовательно, остеомиэлит является заболеванием, в котором принимает участие не только кость и мягкие ткани, а весь организм в целом. Если рассматривать это заболевание с точки зрения павловского учения,

Таблица 3

Титры агглютинннов в крови больного О. к стафилококкам

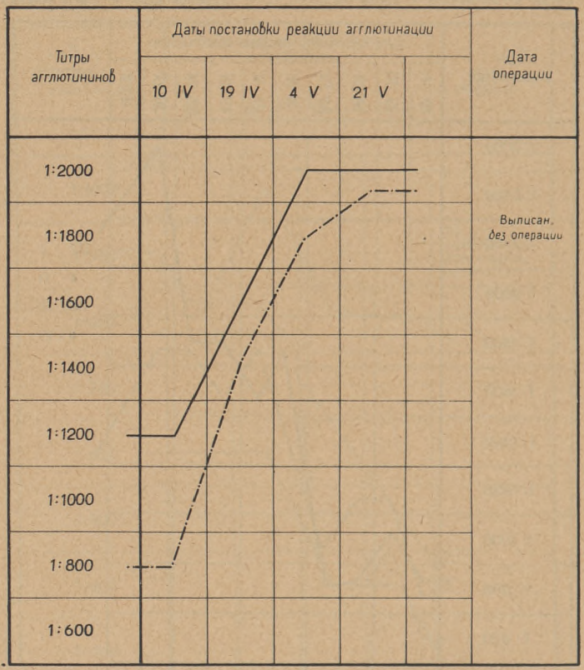

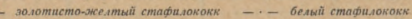

то становится совершенно очевидным, что в остеомиэлитический процесс вовлечена вся иммунологическая система, а следовательно, весь организм в целом.

Кроме того, нами выборочно была поставлена реакция агглютинации сыворотки больных остеомиэлитом с пиококками, выделенными от других больных остеомиэлитом, т. е. так называемая перекрестная реакция агглютинации. Результативные данные показали, что положительная реакция агглютинации с гетерогенной сывороткой получалась в разведениях 1:100-1:200 и не превышала разведения $1: 400$, тогда как с 
собственной сывороткой больното пиококки агтлютинировались, как правило, в разведении 1:1000-1:3000.

И, наконец, также выборочно ставилась реакщия агглютинащии сыворотки больных остеомиэлитом с пиококками, выделенными из воздуха, у которых отсутствовали какие-либо признаки патогенностн (сапрофитами).

Из 29 сывороток 27 дали отрицательную реакцю агтлютинации, одна дала положительный результат в разведении 1: 100 и одна - в разведении 1:200.

Все указанные данные позволяют сделать вывод, что при хроническом остеомиэлнте в крови больных имеются в достаточно большом количестве агглютинины, которые образуются в ответ на раздражение иммунологи ческой системы организма стафилококками и стрептококками, находящимися длительное время в ране. Данные контрольных и сравнительных опытов ясно указывают на выраженную специфичность агглютининов при остеомнэлите.

Следовательно, на микробов раневой инфекции и, в частности, на стафилококков и стрептококков при остеомиялитах нельзя смотреть как на пассивный агент раны, не приносящий организму вреда, а наоборот, они являются сравнительно активными участниками гнон̆ного инфекцнонного процесса и входят в теснейшую взаимосвязь с макроорганнзмом в целом.

Наличие иммунологических сдвигов в организме в виде нарастания и падения титров агглютннинов в крови больных остеомиэлитом должно внести некоторую ясность в вопрос о значении пиококков в течение раневого пропесса и опровергнуть тезис о безучастности микрофлоры раны в течении клинического процесса при остеомиэлите.

Кроме того, установление наличия агтлютининов и их динамики в крови больных остеомиэлитом позволяет клиницистам получнть более ясное представление о течении гнойного процесса с точки зрения прогноза и выбора того или иного метода дальнейшего лечения данного заболевания.

\section{Выводы}

1. Стафилококки и стрептококки, находящиеся в ране при хроническом остеомиэлите, являются в большинстве своём патогенными н антигенно активными микроорганизмами.

2. Наличие агглютининов в крови больных хроническим остеомиэлитом и динамика их титра показывают, что пиококки, находящиеся длительное время в ране, способны в достаточно высокой степени раздражать иммунологическую систему организма, которая продуширует антитела - агглютинины, показывая тем самым, что макроорганизм вступил в активную иммунологическую фазу борьбы с микробами.

3. По наличию в крови больных хроническим остеомиэлитом агглютининов к стафилококкам и стрептококкам можно суднть не только об анатомическом, но и о бактериальном выздоровлении организма, что имеет большое практическое значение для прогноза и нзбрания метода дальнейшего лечения данного заболевания. 


\section{ЛИТЕРАТУРА}

1. Н. Н. А н ичков, Учение о ретикулоэндотелиальной системе, Ленинград, 1930.

2. Г. Д. Бе лоно в ский, Динамнка иммунитета. Изд. АН СССР, Ленннград, 1944.

3. А. В. Благовещенский, Ферменты и явлення иммунитета. Арх. биологич. наук, вып. $3, N_{2} 12,1941$.

4. Г. В, Выгод чи ков, Матерналы к изучению антигенности и иммуногенности стафилококкового анатоксина, ЖМЭИ, 스 12, 1945.

5. Е. Я. Выренков н Е. Г. Шелернна, Цитологическая картина раневого экссудата ирн огнестрельном остеомнэлите, еГоспитальное дело» N. 12, 1944.

6. П. Ф. Г а малея, Инфекщия и иммунитет Медгиз, 1939.

7. П. Л, Г ерби льский, Реакция костного мозга при огнестрельном остеомиэлите, «Вестник хирургин», т. 64, № 3, 1944.

8. Н. И. Г ращенков, П. П. Сахаров н Е. И. Гудкова, Значение клиннкобактернологических и клинико-иммунологических параллелей в учении о раневой инфекции, ЖМЭИ, Nㅜ 7-8, 1945.

9. Н. И. Г ращенков и П. П. Сахаров, Раневые ннфекцин. Газета жмедицинский работнику, № $5,1945$.

10. Н. И. Гращенков и П. П. Саха ров, Клинико-бактериологические и иммунологические параллели при различных ранениях. Труды конференции по раневым ннфекциям, 1946.

11. И. Н. Г реков, Латентная ннфекция и рецидивируюшие остеомиялиты Новый хнр. арх., т. 4 , № $15-16,1924$.

12. C. M. Д ерн жанов, Патологическая анатомия и патогенез остеомиялита, Смоленск, 1940.

13. Л. А. 3 иль 6 ер и Л. М. Я коб сон, Об одном из возможных механизмов естественного иммунитета, ЖМЭИ, № 3, 1946.

14. Л. А. 3 н ль бе р, Оеновы нммуннтета, Медгиз, 1948.

15. В. И. Иоффе, О мнкробнологическом н иммунологическом анализе ияфекционных процессов, «Клиническая медицина», № 12, 1941.

16. В. И. Иоффе, Об очередной задаче в иммунологическом анализе инфекционных процессов (изучение общей неспецифической устойчивости организма к инфекцин). «Қлиническая медицина», 수 9, 1944.

17. В. И. Иоффе н К. М. Р озенталь, О жпризнаках состояння микроба и их значение в микробиологическом анализе ннфекционного процесса, ЖМЭИ, No 3, 1944.

18. Р. Н. К ац, Отличительные призаки золотистого стафилококка, Ташкент, 1936.

19. П. Г. К орнев, Вопросы раневого остеомиэлита, Медгиз, 1947.

20. П. Н. М а ушакян, Реакця агглютинацин прн стафнлодермитах, ЖМЭИ. № 11, 1940.

21. А. Р. Р усанов, Об явлениях общего н местного иммунитета при гнойнй нифекции и их значение в вопросах лечения, єСоветская хнрургня № 1. 1936.

22. 3. В. Т а ран у хнна, Клиническое значение цитологического метода исследований раневого экссудата при раневом сепсисе. Сборннк трудов по раневому сепснсу, Медгиз, 1947.

23. Л. И. Х атеневе р, Қ ученно об инфекщнн и иммунитете. Сборник трудов Контрольного инстнтута, 1944. 